\title{
Statistical analysis of power output from a single heaving buoy WEC for different sea states
}

\author{
A. Savin ${ }^{1} \cdot$ I. Temiz ${ }^{1} \cdot$ E. Strömstedt ${ }^{1} \cdot$ M. Leijon ${ }^{1}$
}

Received: 4 December 2017 / Accepted: 19 September 2018 / Published online: 12 October 2018

(c) The Author(s) 2018

\begin{abstract}
Output power fluctuations from a wave energy converter (WEC) utilizing the principle of an oscillating body are unavoidable due to the reciprocating movement of the translator inside the generator. Moreover, the wave energy flux largely varies with time and propagates with the wave group velocity. Making use of the oscillating output power is a challenge for many wave energy conversion concepts. Therefore, estimation of the output power from a WEC solely by the mean power does not fully reflect the process of energy conversion, especially, by a direct drive linear generator. In the present paper, the output power from the WEC with a linear generator power take-off (PTO) is considered as a stochastic process, and the WEC performance is evaluated from the statistical point of view and related to the linear generator's (LG) stroke length. Statistics as mean, standard deviation, relative standard deviation, maximum, and mode are found for different sea states. All statistics have shown an expected overall tendency with a rising significant wave height of incoming waves. As the significant wave height increases, statistics of the power output such as mean, standard deviation, maximum, and quantile are increasing, and the mode is decreasing beside the mode for the sea state $\mathrm{C}$. It has been noted that for a significant wave height equal to the LG's stroke length, the mode is greater than the same values for sea states of other significant wave heights. The results are based on a full-scale offshore experiment and may be used for the design of energy conversion systems based on a linear generator PTO.
\end{abstract}

Keywords Wave energy converter $\cdot$ Power output $\cdot$ Offshore experiment $\cdot$ Statistical analysis

\section{Introduction}

There are a number of wave energy conversion technologies around the world [1-4]. This paper deals with the wave energy converter (WEC) based on the principle of a point absorber with a direct drive linear generator PTO. This wave energy conversion concept has been developed at the Swedish Center for Renewable Electric Energy Conversion, Ångström Laboratory, Uppsala University. The first full-scale

A. Savin

andrej.savin@angstrom.uu.se

I. Temiz

Irina.Temiz@angstrom.uu.se

E. Strömstedt

Erland.Stromstedt@angstrom.uu.se

M. Leijon

mats.leijon@icloud.com

1 Division of Electricity, Department of Engineering Sciences, Ångström Laboratory, Uppsala University, Uppsala, Sweden linear generator was launched offshore at the Lysekil wave energy research site outside the Swedish west coast in March 2006 [5-7]. The present paper uses measurement data from a full-scale offshore experiment WESA (Wave Energy for a Sustainable Archipelago) conducted at the Hammarudda research site close to the town of Mariehamn, The Alland Islands [8], see Fig. 1.

Waves in a fully developed sea are stochastic $[9,10]$. A point absorber has its natural resonance frequency lying at relatively high frequencies of ocean gravity waves' frequency range, thereby, it follows the wave elevation, and its motion is random by nature. For the considered WEC design, the buoy of toroidal shape is directly connected to the translator moving inside the generator. Therefore, the translator motion, currents, and voltages induced in the stator windings, and as a result, the output power are stochastic processes too. Thus, we consider the absorbed energy for a given time period as a random quantity and evaluate the WEC design from this point of view. 

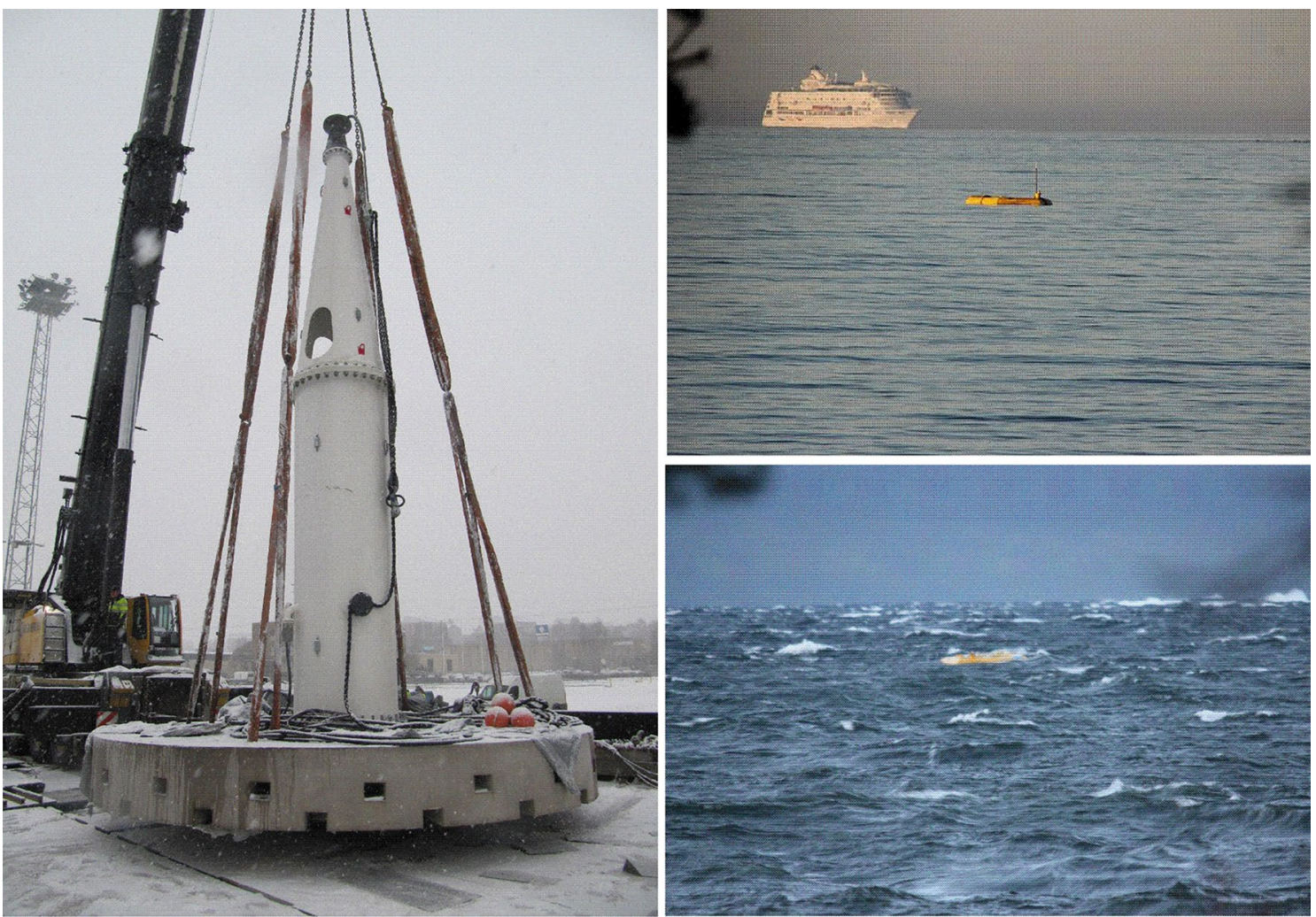

Fig. 1 Full-scale offshore experiment, The Åland Islands

Power absorbed and converted by a single WEC varies significantly within several seconds due to the variability of energy available in ocean waves [11]. Theoretical $[12,13]$ and experimental [14] studies on wave power farms demonstrated a reduced power fluctuation at the farm level compared to the output power of a single device. Recent research on WECs arrays was focused on interaction between devices and WECs array optimization (see, e.g., $[15,16])$.

A direct-driven LG performance for wave energy conversion application, the WEC power output for different sea states and its relation to the generator stroke length are studied in the paper. For a WEC with an LG PTO, the maximum instantaneous output power and mean power can differ greatly, which suggests that estimating power output from the WEC by the mean power does not fully reflect the process of energy conversion by a direct drive linear generator. Comparison of statistical parameters of power output from a single heaving buoy WEC for different sea states is of importance in this case.

\section{Methodology}

\subsection{WEC design}

The WEC consists of a linear direct-driven generator placed on the sea floor as shown in Fig. 2. When the buoy moves with the waves, the translator will get a reciprocal vertical motion in the generator, and a voltage is induced in the stator windings.

The translator mounted with permanent neodymium-iron-boron magnets $\left(\mathrm{Nd}_{2} \mathrm{Fe}_{14} \mathrm{~B}\right)$ covers $100 \%$ of the stator in the middle of the structure. It has a tetragonal translator with a length and a width of $2132 \mathrm{~mm}$ and 400 $\mathrm{mm}$, respectively, for each face. Four stator packages have a length of $1199 \mathrm{~mm}$ for each package, see Fig. 2 and Table 1. The free stroke length, when the translator does not touch either of the end stop springs, is $1244 \mathrm{~mm}$. The 
Fig. 2 WEC inner structure and dimensions

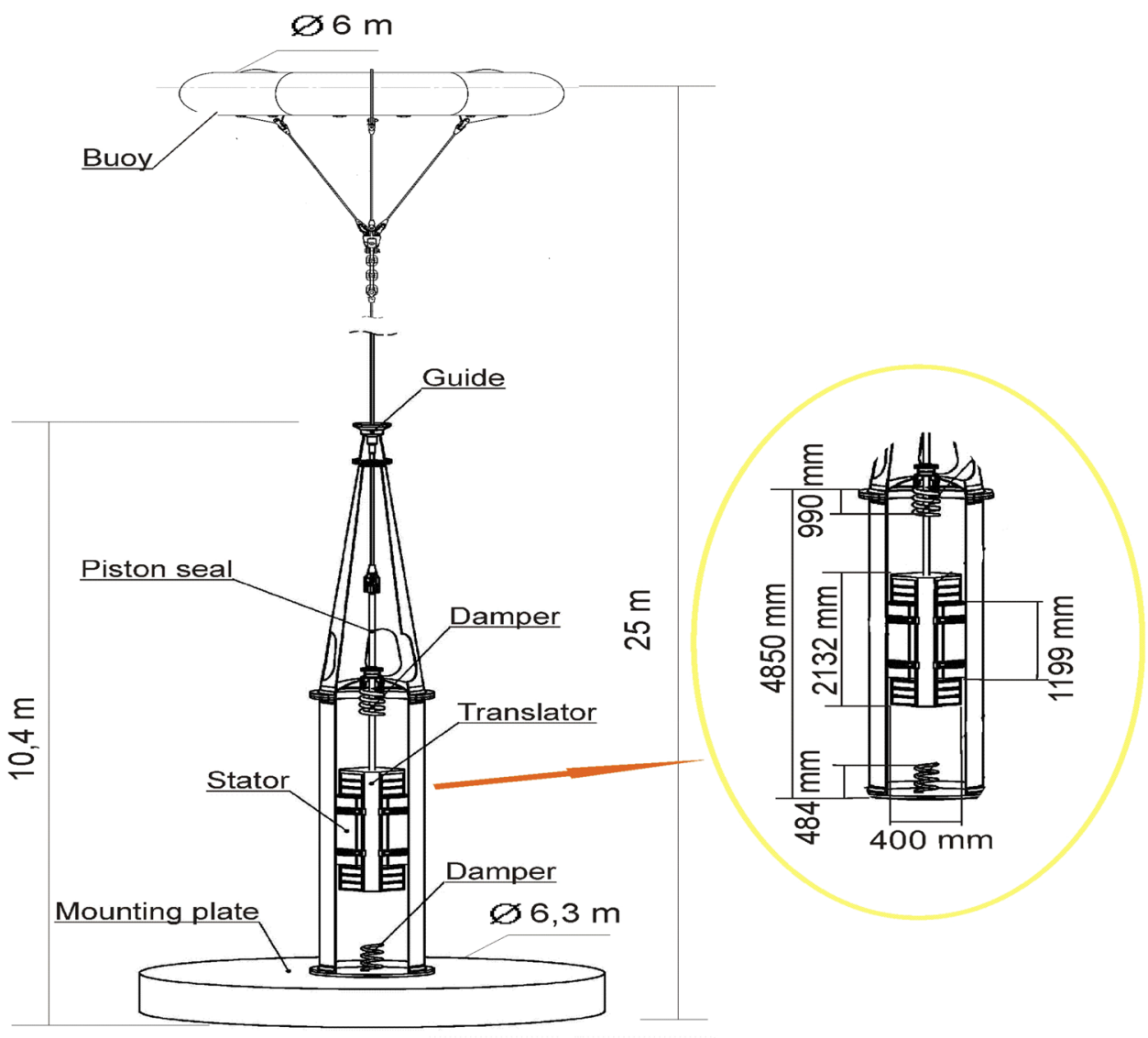

Table 1 Parameters for the generator

\begin{tabular}{ll}
\hline Generator length with foundation & $10,400 \mathrm{~mm}$ \\
Stator length & $1199 \mathrm{~mm}$ \\
Translator length & $2132 \mathrm{~mm}$ \\
Translator width & $400 \mathrm{~mm}$ \\
Nominal power at $0.7 \mathrm{~m} / \mathrm{s}$ & $17.1 \mathrm{~kW}$ \\
Number of electrical phases & 3 \\
Number of stator sides & 4 \\
Translator weight & $5000 \mathrm{~kg}$ \\
\hline
\end{tabular}

end stops springs begin to dampen translator motion with strong damping when the upper-end stop spring is compressed by $90 \mathrm{~mm}$ and the lower end stop spring by 70 $\mathrm{mm}$. Therefore, the total stroke length of the generator is $1404 \mathrm{~mm}$.

The end stop springs used for this experiment consist of a series stack of disk springs: 36 springs are at an upperend stop and 29 springs are at lower end stop. Disk springs have a number of advantageous properties compared to other types of springs, namely, very large loads can be supported with a small installation space as well as a long service life under dynamic loads.
Table 2 Sample time records of sea states

\begin{tabular}{lllll}
\hline Sea state & Time period & $H_{\mathrm{s}}(\mathrm{m})$ & $T_{\mathrm{e}}(\mathrm{s})$ & $\begin{array}{l}\text { Energy } \\
\text { flux } \\
(\mathrm{kW} / \mathrm{m})\end{array}$ \\
\hline $\mathrm{A}$ & Nov. 2, 21:41-22:41 & 0.8 & 4.8 & 1.5 \\
$\mathrm{~B}$ & Oct. 31, 20:40-21:40 & 1.2 & 4.4 & 3.1 \\
$\mathrm{C}$ & Nov. 2, 07:41-08:41 & 1.4 & 5.6 & 5.3 \\
$\mathrm{D}$ & Nov. 1, 07:40-08:40 & 1.6 & 5.1 & 6.4 \\
$\mathrm{E}$ & Oct. 29, 16:41-17:41 & 2.2 & 5.6 & 13.3 \\
$\mathrm{~F}$ & Oct. 29, 18:41-19:41 & 2.4 & 5.9 & 16.7 \\
\hline
\end{tabular}

\subsection{Sample time history records}

Six sample records have been used for power fluctuation estimation corresponding to different sea states, as presented in Table 2 and original and smoothed wave power density spectra are plotted in Fig. 3, where the smoothed wave power density spectra are obtained using moving average with a window of 20 samples. Each sample record has a duration of one hour with a sampling frequency of $100 \mathrm{~Hz}$; the records were made during the period from October 29 to November 2,2012 . The significant wave height of the considered sea states varies between 0.8 and $2.4 \mathrm{~m}$, whereas the energy 

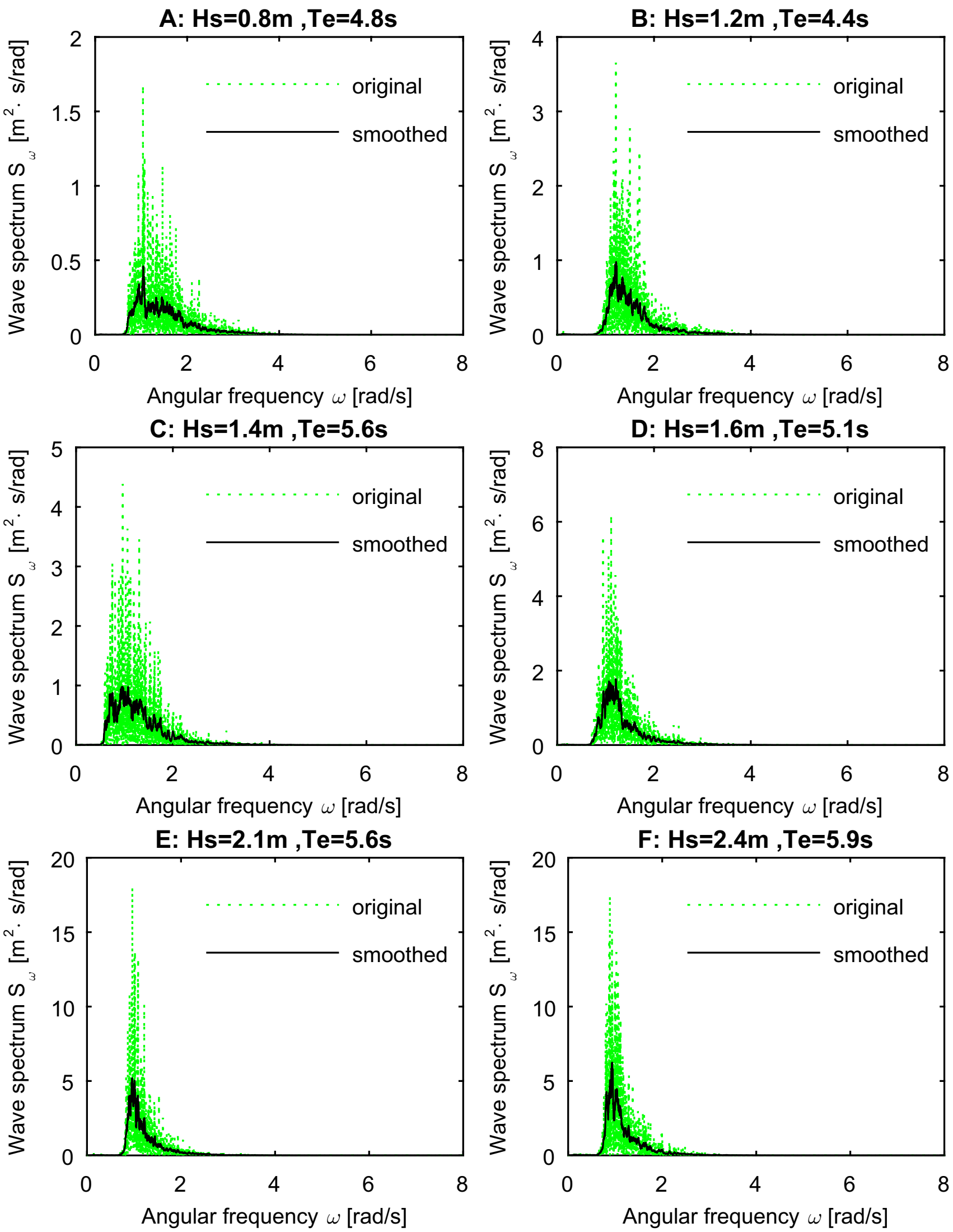

Fig. 3 Original and smoothed wave power density spectra for considered sea states 
Table 3 Evaluated statistical parameters

\begin{tabular}{lllllll}
\hline Sea state & A & B & C & D & E & F \\
\hline Wave energy flux (kW/m) & 1.5 & 3.1 & 5.3 & 6.4 & 13.3 & 16.7 \\
Mean (kW) & 0.91 & 1.96 & 2.36 & 2.97 & 4.91 & 5.04 \\
Standard deviation (kW) & 1.39 & 2.82 & 3.55 & 4.44 & 7.67 & 8.05 \\
Maximum power (kW) & 15.24 & 31.92 & 64.26 & 65.29 & 80.45 & 77.98 \\
99\% quantile (kW) & 6.55 & 13.04 & 16.23 & 20.68 & 38.4 & 40.73 \\
Mode (W) & 1.25 & 1.14 & 1.35 & 1.15 & 1.01 & 0.81 \\
Relative standard deviation & 1.53 & 1.44 & 1.50 & 1.49 & 1.56 & 1.59 \\
99\%-quantile-to-mean & 7 & 7 & 7 & 7 & 7 & 8 \\
Maximum-to-mean & 16.8 & 16.4 & 27.2 & 21.9 & 16.4 & 15.5 \\
\hline
\end{tabular}

period remains close to $5 \mathrm{~s}$, namely, it varies between 4.4 and $5.9 \mathrm{~s}$. A large variation of the significant wave height leads to very large variation in the wave energy flux per meter of the wave crest. In particular, the wave energy flux of the sea state with the lowest energy content is more than ten times less than the energy flux of the sea state with the highest energy content.

Voltages and currents are measured at the output terminals of the WEC in the measurement station located on the shore over $1 \mathrm{~km}$ from the WEC. For any time instant $t$, the instantaneous active output power $P(t)$ is evaluated by the following formula:

$P(t)=R_{Y} \cdot\left(I_{1}^{2}(t)+I_{2}^{2}(t)+I_{3}^{2}(t)\right) \quad[W]$,

where $R_{Y}$ is the $Y$-connected resistive load, and $I_{1}(t), I_{2}(t)$, and $I_{3}(t)$ represent the measured three phase output AC current.

\subsection{Statistics}

For each sea state, the (empirical) probability distribution function (PDF) and the exceedance probability function (EPF) are obtained from a time series of the instantaneous power output $P(t)$. These functions and the samples of $P(t)$ are used to estimate different statistics such as the mean, standard deviation, relative standard deviation, mode, maximum and 99\%-quantile as well as the ratios of the maximum-to-mean power and the $99 \%$-quantile-to-mean power.

\section{Results}

Estimated statistics of the WEC power output for different sea states are presented in Table 3 and illustrated in Fig. 4.

With increasing wave energy flux, the mean electric power output from the WEC increases as well as the standard deviation, 99\%-quantile, and maximum output power. A small decrease in maximum power for the sea state $\mathrm{F}$ compared to the sea state $\mathrm{E}$ can be attributed to differences in individual waves hitting the buoy. A relatively high incident

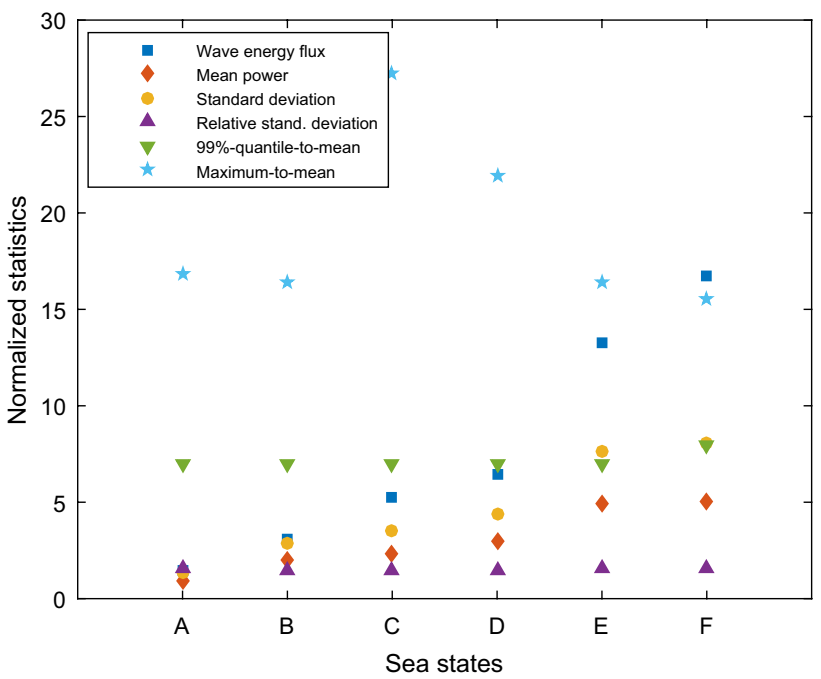

Fig. 4 Statistical parameters and wave energy flux for different sea states (apart from the maximum power and mode due to scaling issues)

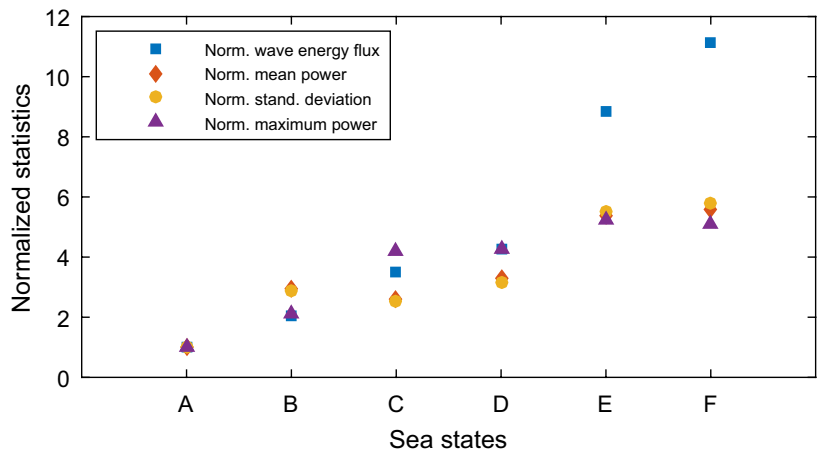

Fig. 5 Normalized statistical parameters and normalized wave energy flux

wave can hit the buoy, although the significant wave height remains low. The relative standard deviation and 99\%-quantile-to-mean ratio are approximately the same for all presented sea states, and the deviations have, perhaps, occurred 
due to variations in incident waves. The largest maximumto-mean ratio corresponds to the sea state with a significant wave height of $1.4 \mathrm{~m}$ and decreases for other sea states with both higher and lower energy content.

Statistics for all sea states normalized by the corresponding parameters of the sea state A are presented in Fig. 5. Comparing the normalized quantities, it can be noted that the increase of the normalized statistics does not occur at the same rate as the increase of the normalized wave energy flux. The difference becomes noticeable for sea states with a significant wave height greater than $1.6 \mathrm{~m}$.

In Figs. 6 and 7, the empirical PDF for different sea states is plotted on the interval from $0 \mathrm{~W}$ to $2 \mathrm{~W}$. Filled circles are used to denote the modes for each sea state. The empirical PDFs have been obtained by means of the normal (Gaussian) kernel smoothing function estimate (ksdensity, Matlab) with the bandwidth of 0.05 that has been chosen to make the PDF closer to the initial data sample. The estimated EPFs are plotted in Fig. 8. The EPFs for sea states B, C, and D are very close to each other, and the EPFs for sea states $\mathrm{E}$ and F nearly overlap.

\section{Discussion}

For a sea state given by significant wave height $H_{\mathrm{s}}$ and energy period $T_{\mathrm{e}}$, the wave energy flux is proportional to $H_{\mathrm{s}}^{2} T_{\mathrm{e}}$. Therefore, an increasing significant wave height has a greater impact on wave energy available in incident waves, which in turn, impacts performance of a WEC, especially with a direct drive PTO. For the sea states considered in the paper, energy periods vary about $5 \mathrm{~s}$ by less than $20 \%$, whereas the significant wave height of sea state $\mathrm{F}$ is three times greater than the one of sea state A. Thus, the authors discuss results in terms of significant wave heights rather than energy periods.

The sea state $\mathrm{C}$ with a significant wave height of $1.4 \mathrm{~m}$ is the closest to the generator stroke length. When the

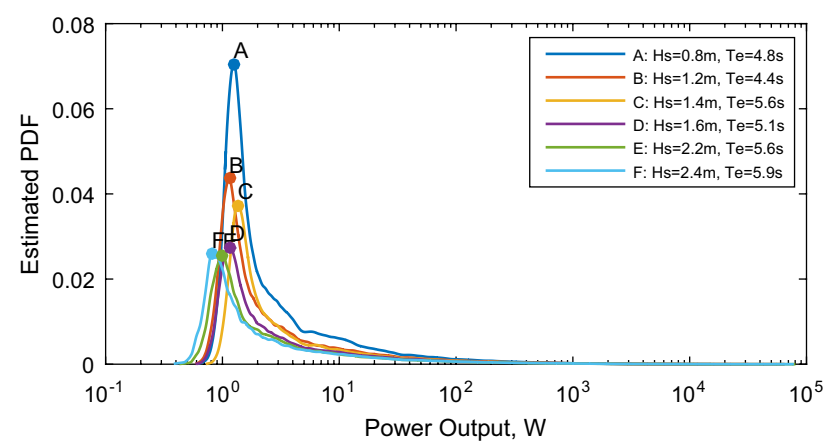

Fig. 6 Estimated probability density function for the whole data range. Filled circles denote the modes for each sea state

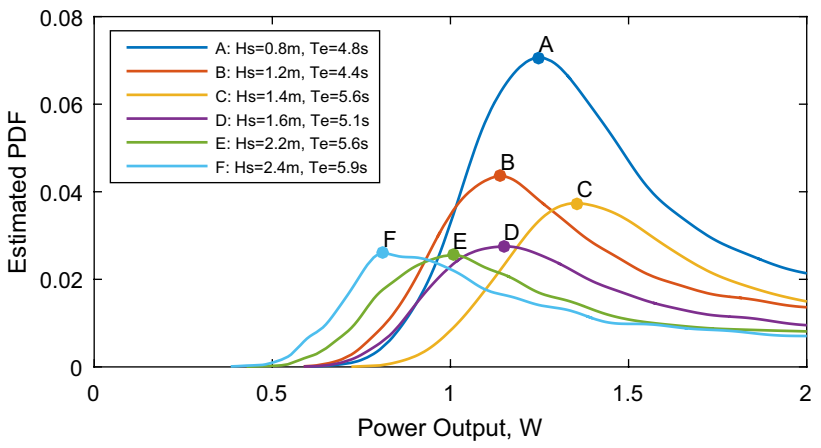

Fig. 7 Enlarged plots of estimated probability density function given in Fig. 6 Filled circles denote the modes for each sea state

significant wave height is noticeably greater than this value (sea states $\mathrm{E}$ and $\mathrm{F}$ in Fig. 5), the WEC's power absorption is reduced to a large extent. The modes tend to decrease for all presented sea states besides the one with a significant wave height of $1.4 \mathrm{~m}$ that is the closest quantity to the generator stroke length. It could arise, because the time period when the translator velocity is close to zero is very short.

As the significant wave height increases, statistics of the power output such as mean, standard deviation, maximum, and quantile are increasing, and the mode is decreasing beside the mode for $H_{\mathrm{s}}=1.4 \mathrm{~m}$. It has been noted that the relative standard deviation is approximately the same for different sea states which can be seen as a property of the linear generator output power.

Regarding the mean output power, the largest value is obtained for $H_{\mathrm{s}}=2.4 \mathrm{~m}$. Nonetheless, this value is reached rather due to very large maximum values and, in turn, larger variation in the output power than due to better performance of the generator. This is illustrated by a very low mode which can be caused by longer time period, while the translator stays still at either end stop. It can be observed from the data that directly driven linear generators face very high maximum-to-mean ratios.

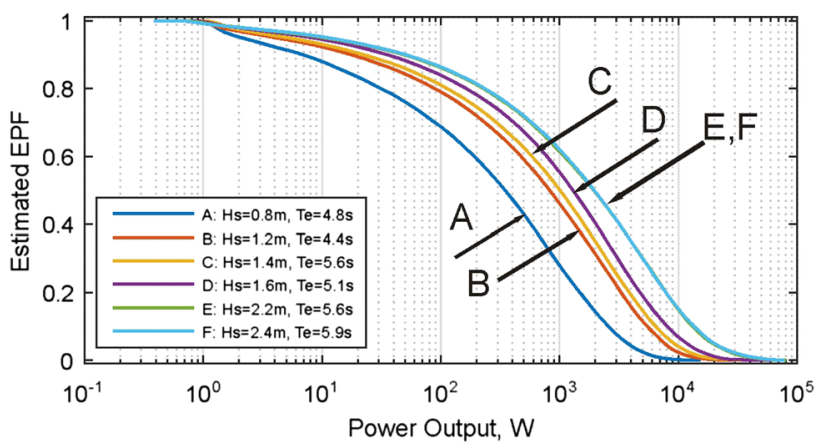

Fig. 8 Estimated exceedance probability functions 
The mode of the distribution corresponding to the sea state of $H_{\mathrm{s}}=1.4 \mathrm{~m}$ is out of the descending tendency. Dropping of the output power to zero is unavoidable due to an inherent property of an LG [17], i.e., reciprocal motion and varying velocity of the translator and varying magnetic flux through the stator coils. However, if the motion amplitude is constrained by the stroke length, then the stand-still time when the translator motion direction changes to the opposite one increase.

In a series stack of disk springs, the deflection is not exactly proportional to the number of springs. This is because of a bottoming out effect when the springs are compressed as the contact surface area increases once the spring is deflected beyond 95\%. Hysteresis (load losses) occurs due to friction between the springs, that is advantageous for the considered system because of the added damping and energy dissipation lead to inertia reduction of the translator but, on the other hand, result in a higher standard deviation of output power.

\section{Conclusions}

In the present paper, we have considered the power output from the WEC with an LG PTO as a stochastic process and evaluated its performance from a statistical point of view.

Statistics as mean, standard deviation, relative standard deviation, maximum, and mode have been evaluated for different sea states. All statistics have shown an expected overall tendency with a rising significant wave height of incoming waves.

It was observed that the relative standard deviation and the ratio of $99 \%$-quantile to the mean are almost the same for this type of the WEC regardless of the sea state. We assume that it is a general property of this WEC type.

It has been noted that for a significant wave height of $1.4 \mathrm{~m}$, the mode is greater than the same parameters for the other sea states. It can be explained by the fact that the stroke length of the generator is approximately equal to $1.4 \mathrm{~m}$, and almost no stand-still periods arose when the translator was at its upper and lower turning positions. However, the reasonableness of making a longer linear generator needs to be studied further regarding installed costs, reliability, and feasibility.

As it was mentioned before, dissipation of energy by a series stack of disk springs means inertia reduction of the translator, and as a result, a higher standard deviation of output power. The authors propose to minimize the standard deviation of output power by a longer stroke length of the linear generator as well as using compression springs instead of a series stack of disk springs. Compression springs will mainly accumulate the kinetic energy of the translator as potential energy instead of dissipating it as heat which will increase the inertia of the translator and, as a result, electricity production.

Acknowledgements This work was financially supported by Uppsala University, Sweden, and Central Baltic Interreg IV A Programme, WESA project (Wave energy for a sustainable archipelago), CFE-III, Swedish Energy Agency, StandUp for Energy.

Open Access This article is distributed under the terms of the Creative Commons Attribution 4.0 International License (http://creativeco mmons.org/licenses/by/4.0/), which permits unrestricted use, distribution, and reproduction in any medium, provided you give appropriate credit to the original author(s) and the source, provide a link to the Creative Commons license, and indicate if changes were made.

\section{References}

1. R. Henderson, Design, simulation, and testing of a novel hydraulic power take-off system for the Pelamis wave energy converter. Renew. Energy 31, 271-283 (2006)

2. Jens Peter Kofoed, Peter Frigaard, Erik Friis-Madsen, Hans Chr Sorensen, and and, Prototype testing of the wave energy converter wave dragon. Renew. Energy 31, 181-189 (2006)

3. A.P. McCabe, A. Bradshaw, J.A.C. Meadowcroft, G. Aggidis, Developments in the design of the PS Frog Mk 5 wave energy converter. Renew. Energy 31, 141-151 (2006)

4. D. Elwood, C. Solomon, J. Prudell, C. Stillinger, A. Jouanne, T. Brekken, A. Brown, R. Paaschs, Design, construction, and ocean testing of a taut-moored dual-body wave energy converter with a linear generator power take-off. Renew. Energy 35, 348354 (2010)

5. M. Leijon, Hans Bernhoff, Olov Ågren, Jan Isberg, Jan Sundberg, Marcus Berg, Karl Erik Karlsson, Arne Wolfbrandt, Multiphysics simulation of wave energy to electric energy conversion by permanent magnet linear generator. IEEE Trans. Energy Convers. 20(1), 219-224 (2005)

6. K. Nilsson, M. Grabbe, K. Yuen, M. Leijon, A direct drive generator for marine current energy conversion-first experimental results. in 7th European Wave and Tidal Energy Conference, 11-13 September (2007)

7. M. Leijon, C. Boström, O. Danielsson, S. Gustafsson, K. Haikonen, O. Langhamer, E. Strömstedt, M. Stålberg, J. Sundberg, O. Svensson, S. Tyrberg, R. Waters, Wave energy from the North Sea: experiences from the Lysekil research site. Surv. Geophys. 29, 221-240 (2008)

8. E. Strömstedt, A. Savin, H. Heino, K. Antbrams, K. Haikonen, T, Götschl, Project WESA (Wave Energy for a Sustainable Archipelago) - a Single Heaving Buoy Wave Energy Converter Operating and Surviving Ice Interaction in the Baltic Sea. in Proceedings of the 10th European Wave and Tidal Energy Conference (EWTEC 2013), Aalborg, 2-5 Sept (2013)

9. M.A. Stelzer, R.P. Joshi, Evaluation of the wave energy generation from buoy heave response based on linear generator concepts. J. Renew. Sustain. Energy 4, 063137 (2012)

10. A.P. McCabe, G.A. Aggidis, Optimum mean power output of a point-absorber wave energy converter in irregular waves. Proc. Inst. Mech. Eng. Part A J. Power Energy 223, 773-781 (2009)

11. Jan Isberg, Mikael Eriksson, Mats Leijon, Transport of energy in polychromatic fluid gravity waves. J. Eng. Math. 64, 15-23 (2009)

12. J. Tissandier, A. Babarit, A.H. Clement, Study of the smoothing effect on the power production in an array of SEAREV wave 
energy converters. in Proceedings of the 18th International Offshore and Polar Engineering Conference, Vancouver, 6-11 July (2008)

13. A. Babarit, B. Borgarino, P. Ferrant, A. Clement, Assessment of the influence of the distance between two wave energy converters on energy production. IET Renew. Power Gener. 4, 592-601 (2010)

14. M. Rahm, O. Svensson, C. Bostrom, R. Waters, M. Leijon, Experimental results from the operation of aggregated wave energy converters. IET Renew. Power Gener. 6, 149-160 (2012)
15. J. Engström, M. Eriksson, M. Göteman, J. Isberg, M. Leijon, Performance of large arrays of point absorbing direct-driven wave energy converters. J. Appl. Phys. 204502, 1-6 (2015)

16. M. Göteman, J. Engström, M. Eriksson, J. Isberg, M. Leijon, Methods of reducing power fluctuations in wave energy parks. J. Renew. Sustain. Energy 6, 043103 (2014)

17. M.A. Mueller, N.J. Baker, E. Spooner, Electrical Aspects of Direct Drive Wave Energy Converters. in 4th European Wave Energy Conference, Aalborg (2000) 